\title{
Transpiration dynamics support resource partitioning in African savanna trees and grasses
}

\author{
Ricardo M. Holdo ${ }^{1,3}$ and Jesse B. Nippert ${ }^{2}$ \\ ${ }^{1}$ Divison of Biological Sciences, University of Missouri, Columbia, Missouri 65211 USA \\ ${ }^{2}$ Division of Biology, Kansas State University, 106 Ackert Hall, Manhattan, Kansas 66506 USA
}

\begin{abstract}
It is still far from clear whether and to what extent trees and grasses partition soil moisture in tropical savannas. A major reason for this is that we don't know how snapshot data on rooting differences translate into ecologically relevant patterns of water use at seasonal scales. We used stable isotopes in soil and stem water to quantify functional rooting profiles in grasses and two tree species in a South African savanna. Concurrently, we measured tree sap-flow velocity, grass canopy temperature (a transpiration correlate), and soil moisture content at multiple depths over the course of a growing season. We used lasso regression to identify the dominant soil moisture layers driving daily variation in tree and grass water-use metrics while controlling for weather variables. We found clear rooting depth differences between grasses (shallow) and trees (deep) from the isotopic data, and these patterns were strongly supported by the water-use data, which showed that grasses and trees predominantly responded to soil moisture availability at 5 and $40 \mathrm{~cm}$ depth, respectively. Our results provide a rare example of mechanistic support for the resource partitioning hypothesis in savannas, with important implications for our understanding of tree-grass dynamics under altered precipitation regimes.
\end{abstract}

Key words: canopy temperature; lasso regression; niche partitioning; rooting depth; sap flow; South Africa; stable isotopes; water use.

\section{INTRODUCTION}

Global climate change-driven shifts in rainfall regimes (e.g., altered frequency and size of precipitation events) have the potential to shift the vertical distribution of soil moisture in soil profiles, with potentially important consequences for the performance and relative abundance of shallow- and deep-rooted plant species (Kulmatiski and Beard 2013b). Several temperate systems with mixtures of woody and herbaceous vegetation provide a stark example of this rooting-depth dichotomy, showing clear evidence for rooting differentiation between trees (or shrubs) and grasses (Sala et al. 1989, Weltzin and McPherson 1997, Nippert and Knapp 2007), as reviewed by Ward et al. (2013). Such evidence is mixed in the tropical and subtropical savannas that comprise almost half of the African land mass, and there is disagreement about the extent to which trees and grasses partition soil moisture in these systems (Verweij et al. 2011, Kambatuku et al. 2013, Kulmatiski and Beard 2013a, Ward et al. 2013). Resolving the significance of resource partitioning in savannas has important consequences for predicting changes in tree-grass ratios under novel climate regimes.

Manuscript received 20 October 2014; revised 13 January 2015; accepted 4 February 2015. Corresponding Editor: J. B. Yavitt.

${ }^{3}$ E-mail: holdor@missouri.edu
Much of the evidence for or against the nichepartitioning hypothesis derives from studies of treegrass rooting depth differences (Roux et al. 1995, Mordelet et al. 1997, Kulmatiski and Beard 2013a). It has been argued, however, that even when these differences exist, trees and grasses largely compete for moisture from the upper soil layer, so niche partitioning does not necessarily occur (Rodríguez-Iturbe et al. 1999). The argument against niche partitioning also highlights that most precipitation in tropical savannas falls during the warm growing season (unlike the case for many temperate tree-grass systems), and therefore little deep infiltration occurs (Rodríguez-Iturbe et al. 1999). Manipulative experiments on tree-grass competitive interactions from tropical savannas (as opposed to rooting-depth studies) have also found strong competitive effects between grasses and trees (Riginos 2009, Verweij et al. 2011, February et al. 2013), although these effects may be context dependent (Knoop and Walker 1985). Holdo (2013) provided a framework for this context by showing theoretically that the extent to which rooting-depth differentiation leads to niche partitioning should depend both on soil and climate variables, and that where conditions are conducive to deep water infiltration, niche partitioning is possible and probably common. The extent to which partitioning occurs may also vary across tree species (Ward et al. 2013)

We propose that measurements of plant responses to soil water availability at different depths will greatly 
improve our understanding of rooting niches. At present, direct mechanistic evidence for niche partitioning is lacking. To address this gap, we conducted a study in a lowveld savanna ecosystem in South Africa designed to quantify and compare water-use responses of trees and grasses to soil moisture availability at contrasting depths. We tested the hypothesis that trees and grasses demonstrate physiological responses to water availability at different soil depths as a result of their rooting differences. We achieved this by quantifying the relationship between indices of water use (sap flow in trees and canopy temperature in grasses) and soil moisture at four depths over the course of a growing season.

\section{Material and Methods}

\section{Study system and data collection}

We conducted the study at Wits Rural Facility, Limpopo Province, South Africa, between 8 December 2011 and 15 May 2012, timed to coincide with the wet season, when plant physiological activity is highest. The area is dominated by lowveld savanna (see Plate 1) on highly weathered sandy soils. The climate is semiarid, with a mean annual precipitation of $679 \mathrm{~mm}(\mathrm{SD}=211)$, $90 \%$ of which falls between November and April. The site is dominated by tree species such as Terminalia sericea and Combretum collinum, Schlerocarya birrea, and Pterocarpus angolensis, as well as several species of $\mathrm{C}_{4}$ perennial grasses such as Themeda triandra and Panicum maximum (Appendix A: Fig. A1).

The size of our study area was constrained by maximum allowable distances $(\sim 30 \mathrm{~m})$ between our sap-flow system enclosure and our experimental trees. After locating a suitable site for the enclosure, we identified the first eight trees of each of the two most common species (Terminalia sericea and Pterocarpus angolensis) that fell within this distance, and that had a basal diameter between 10 and $20 \mathrm{~cm}$ (we had one tree each slightly above and below this range). In December 2011, we equipped each tree with one or two (for some of the larger trees) Granier-type (Granier 1985, Paço et al. 2009) thermal dissipation probes (30 $\mathrm{mm}$ in length; Dynamax TDP30; Dynamax FLGS-TDP XM1000 Sap Velocity System, Dynamax, Houston, Texas, USA). The probes use the temperature differential between a heated and a reference needle to quantify sap flow, based on a 45/15-min on/off cycle to correct for natural thermal gradients. We also set up a weather station and buried soil moisture probes at multiple locations and depths. To collect weather data, we connected a HOBO Micro Station datalogger to the following sensors: a photosynthetically active radiation (PAR) sensor, a tipping bucket-type rain gauge, an anemometer, and a temperature/RH (relative humidity) sensor (Onset Computer Corporation, Bourne, Massachusetts, USA). To obtain soil volumetric water content (VWC) data, we used eight cabled reflectometers (CS616-L), connected to the CR1000 datalogger (Campbell Scientific, Logan, Utah,
USA) that controls the FLGS sap-flow system. We excavated a main central pit with four cabled sensors at $5,10,20$, and $40 \mathrm{~cm}$ depth, and three additional pits with cabled sensors at 10 and $20 \mathrm{~cm}$ depth. To obtain data on grass water use, we relied on canopy temperature $\left(T_{\mathrm{c}}\right)$ data, which is highly correlated with leaf moisture stress, water potential and stomatal conductance, particularly when corrections are made for other environmental variables (Jones 1999, Cohen et al. 2005, Ben-Gal et al. 2009). $T_{\mathrm{C}}$ declines as transpiration increases due to evaporative cooling. We set up four infrared radiometers (SI-121, Apogee Instruments, Logan, Utah, USA) on poles pointed at the canopies of four individual grass tufts. We ensured that the radiometer field of view would only capture canopy temperature and not background soil temperature data. The radiometers were connected to the CR1000 datalogger. Canopy temperature and sap-flow data were logged at 5-min intervals, and volumetric water content (VWC) at 30min intervals, in both cases with values comprising means calculated from 1-min scan intervals.

At the end of the study in May 2012, we collected soil and plant stem samples for stable isotope analyses. Given that water isotopes fractionate during infiltration (and subsequent evaporation) but not during plant uptake (Nippert and Knapp 2007), the stable isotopic composition of xylem water provides inference about the water source (in terms of depth). We dug three soil pits and collected $10 \mathrm{~g}$ of soil at depths of 5, 10, 20, 30, 40, and $70 \mathrm{~cm}$ from the vertical face of each, taking care to quickly collect samples to minimize evaporative loss. We also set up a $40-\mathrm{m}$ transect along the longest axis of the site and collected soil samples at 5 and $20 \mathrm{~cm}$ every $4 \mathrm{~m}$. We used these data to evaluate the extent to which stable isotope signatures varied spatially within the study site. For plant samples, we collected non-photosynthetic twigs from three branches of each of our 16 trees, and grass culms (Corbin et al. 2005) from five individual grass tufts from areas immediately surrounding each of our soil pits ( $N=15$ total). We immediately placed all samples (soil and plant) in Exetainer vials (Labco, Lampeter, UK) for transport to the United States. We kept the vials frozen prior to water extraction by cryogenic distillation at the University of Missouri. For the extractions, we used an open manifold system that facilitates removal of non-condensable gases and potential organic contaminants (Nippert and Knapp 2007). We analyzed all extracted water using a Picarro L1102-i CRDS analyzer (Picarro, Santa Clara, California, USA) at the Stable Isotope Mass Spectrometry Laboratory at Kansas State University for $\delta \mathrm{D}$ and $\delta^{18} \mathrm{O}$ values.

\section{Data analysis}

Prior to analysis, we calculated mean daily values for all variables over the duration of the study: VWC (Fig. 1c), sap flow velocity (Fig. 1d), grass canopy temperatures (Fig. 1d), and weather variables (Fig. 1e, f). In all

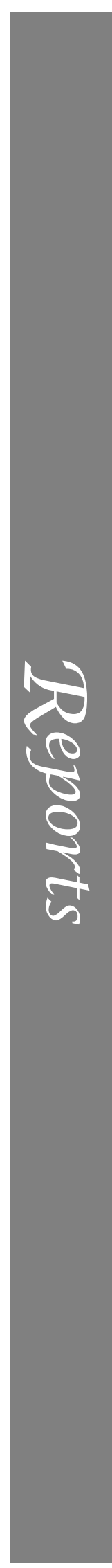



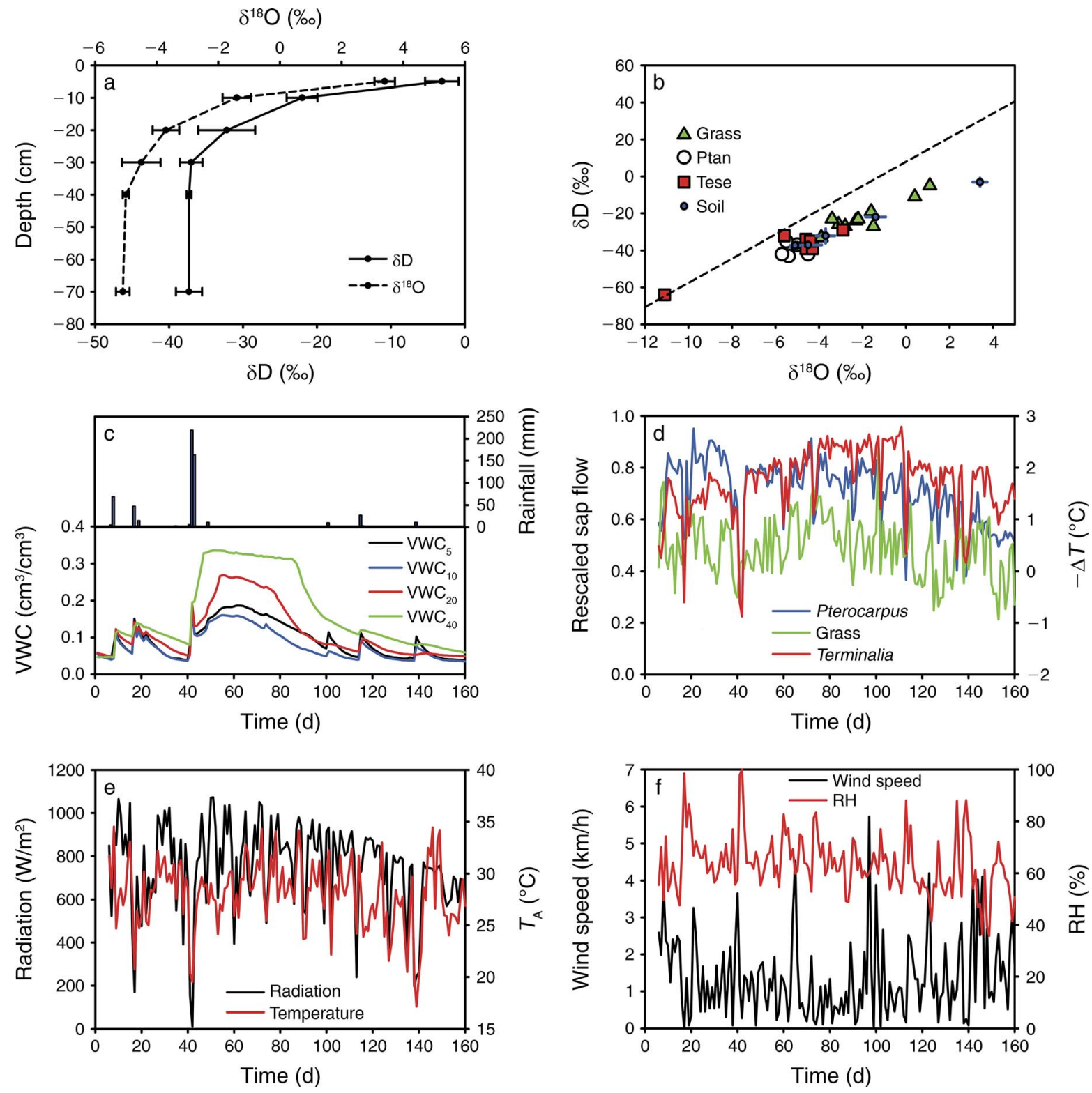

FIG. 1. Distribution (mean $\pm \mathrm{SE}$ ) of soil water stable isotopes $\left(\delta \mathrm{D}\right.$ and $\left.\delta^{18} \mathrm{O}\right)$ as a function of depth, based on (a) $N=3$ for 13 samples per depth and (b) soil and plant stem water (grasses and two tree species, Terminalia sericea [Tese] and Pterocarpus angolensis [Ptan]) values at Wits Rural Facility, South Africa in May 2012. The nearest calculated local meteoric water line (Pretoria) is shown as a dashed line (West et al. 2014). (c) Precipitation and mean daily volumetric soil moisture (volumetric water content, VWC) at four depths $(5,10,20$, and $40 \mathrm{~cm})$; (d) mean daily rescaled (dimensionless) tree sap flow $(N=8$ Terminalia sericea and 8 Pterocarpus angolensis) and grass water use index $-\Delta T$ (see Materials and methods: Data analysis; $N=4$ ); (e) mean daily photosynthetically active radiation (PAR) and ambient temperature $T_{\mathrm{a}}$; and (f) wind speed and relative humidity (RH) are shown over the course of the 2011-2012 wet season (day 0 corresponds to 8 December 2011).

cases, we used only data for the daily period of peak photosynthesis, between 10:00 and 14:00 (Stefan et al. 2014). We rescaled sap flow velocity to vary between 0 and 1 for each tree by dividing mean daily sap flow velocity values by the maximum value for each tree (Fig. 1d). For the grasses, we used two metrics of water use: $T_{\mathrm{c}}$ and $\Delta T=T_{\mathrm{c}}-T_{\mathrm{a}}$, where $T_{\mathrm{a}}$ corresponds to ambient temperature from our weather station. Plant canopy temperature data is usually incorporated into a "crop water stress index" (CWSI) in conjunction with dry and wet leaf reference temperatures (Cohen et al. 2005, Möller et al. 2007), which constitute endpoints for $T_{\mathrm{c}}$ (dry leaves do not transpire and have high temperatures, and vice versa). The temperature of dry leaves, $T_{\mathrm{d}}$, is often assumed to be directly proportional to $T_{\mathrm{a}}$ (Möller et al. 2007), but the nature of our study design precluded 


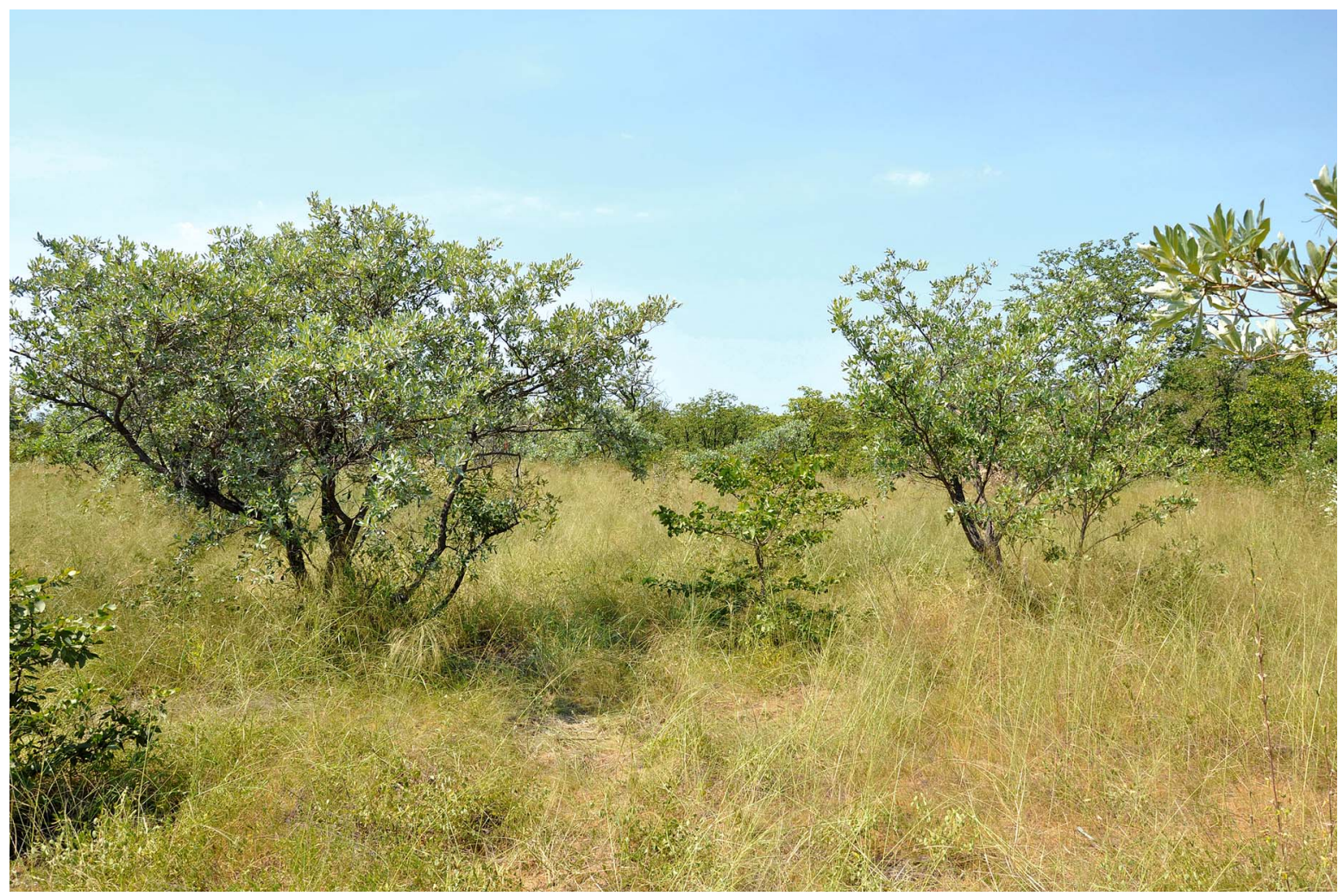

Plate 1. Representative Terminalia sericea-dominated lowveld savanna in Kruger National Park, South Africa. Photo credit: R. M. Holdo.

the continuous automated measurement of the temperature of wet leaves, $T_{\mathrm{w}}$. As with tree sap flow, our aim was to capture an index of relative change in water use across the growing season rather than absolute values of moisture stress (the usual application of CWSI for irrigation timing). Both $T_{\mathrm{c}}$ and $\Delta T$ have been shown to be suitable indices of plant water status (Cohen et al. 2005, Ben-Gal et al. 2009, Stefan et al. 2014). Since these metrics vary inversely with water use, we used $-T_{\mathrm{c}}$ and $-\Delta T$ as response variables in our statistical analysis to make the signs of our regression coefficients comparable across trees and grasses.

To test for a relationship between our transpiration indices and soil moisture availability at each of the four sensor depths, we used a lasso regression to fit models of daily rescaled sap flow, $-T_{\mathrm{c}}$, and $-\Delta T$ for individual trees and grass tussocks to VWC at 5,10,20, and $40 \mathrm{~cm}$ depth $\left(\mathrm{VWC}_{5}-\mathrm{VWC}_{40}\right)$. We calculated mean values across all sensors at a given depth for trees but used sensor data from the central pit for grasses, given the different spatial extents of our tree and grass transpiration data. Given the high degree of multicollinearity across depths in the VWC data (Pearson's $r>0.85$ for any pairwise combination), we required a regression approach capable of teasing apart the effects of highly correlated covariates. Lasso regression (Tibshirani 1996) avoids some of the problems associated with multi- collinearity by shrinking or penalizing parameter estimates to avoid overfitting (unimportant variables are assigned coefficients of zero, and it therefore serves as a de facto model selection algorithm). It has been shown to perform better than other shrinkage techniques in rejecting spurious coefficients when tested with simulated data (Lazaridis et al. 2010). To investigate the ability of the lasso to identify the dominant water sources in our particular data set, we conducted our own simulation, using our VWC data to produce a simulated response variable. We used simple linear models to generate two simulated responses, characterized by nonzero effects of VWC at 5 and $40 \mathrm{~cm}$, respectively (with all other coefficients equal to zero) plus a normallydistributed stochastic component. We made both the deterministic and stochastic components of the response of similar magnitude to those in our lasso model fits. We generated 10000 simulated data sets and used lasso regressions relating the simulated values to the VWC data to assess the ability of the method to recover the "true" driving variables in the simulation.

Plant transpiration is a function both of atmospheric demand and soil moisture supply (Jones 1999). In the case of thermal indices of transpiration based on canopy temperature data, the nature of the relationship between leaf temperature and transpiration itself varies as a function of incoming radiation, wind speed and relative 

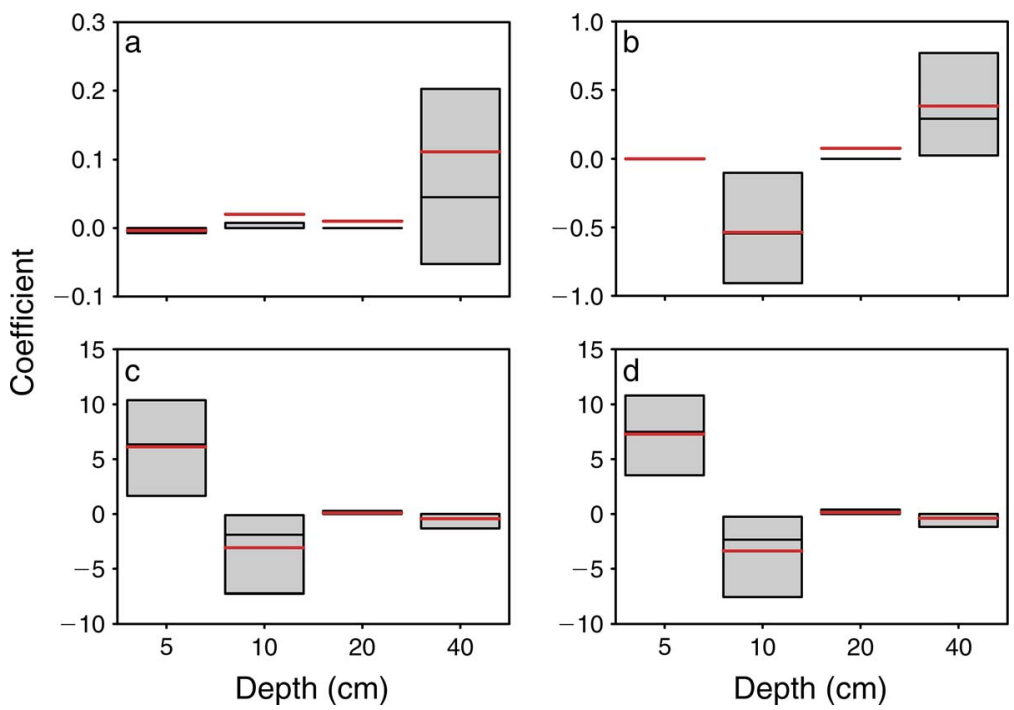

humidity (Jones 1999). In either case, detecting responses to fluctuations in soil moisture availability to some extent requires controlling for the variables that affect demand or the temperature/transpiration relationship. In addition to our first analysis (termed "soil moisture" model) we performed a second analysis that tested for VWC effects on transpiration after accounting for effects of radiation, $T_{\mathrm{a}}, \mathrm{RH}$, and wind speed (the "weather + soil moisture" model). We ran both sets of lasso regressions using the cv.glmnet function in the $\mathrm{R}$ package glmnet (Friedman et al. 2010), which implements a lasso with cross-validation. The lasso algorithm is stochastic, and therefore yields regression coefficients that fluctuate from run to run. We conducted 100 cv.glmnet runs for each sap flow or temperature series, and report both mean coefficient values and the proportion of runs that yielded non-zero coefficient values for each covariate.

\section{Results}

\section{Stable isotope analysis}

The soil stable isotope data revealed a clear monotonic decline in both $\delta \mathrm{D}$ and $\delta^{18} \mathrm{O}$ values as a function of depth, with values reaching an apparent asymptote below about $40 \mathrm{~cm}$ (Fig. 1a). The decline in $\delta \mathrm{D}$ and $\delta^{18} \mathrm{O}$ values with depth was highly consistent across the study site, despite some variability in values at a given depth (Appendix B: Fig. B1), suggesting that the overall pattern found was representative for the site. Grasses $(N=11)$ had shallower (less negative) stable isotope signatures than trees $(N=6$ Pterocarpus and 7 Terminalia; Fig. 1b and Appendix C: Fig. C1), based on an ANOVA on the first principal component of the two stable isotopes $\left(F_{2,21}=12.23, P<0.0005\right)$. A post hoc analysis revealed highly significant differences between the grasses and the two tree species (Pterocarpus $t=4.02, P<0.005$; Terminalia $t=4.16, P<0.005$ ) but not between tree species.

\section{Tree sap flow and grass canopy temperature}

We obtained between 95 and 160 daily sap flow values for 15 of our 16 study trees with missing values attributable to periodic sensor failure, and 160 daily grass canopy temperature values for each of our four grass tufts. Tree $\mathrm{T} 1$ had only 41 observations and was an outlier in terms of sample size. For our first model (soil moisture effects only), the lasso regression suggested that daily variation in rescaled tree sap flow was predominantly positively associated with VWC recorded by our deepest sensor $\left(\mathrm{VWC}_{40}\right)$, with five of eight Pterocarpus and seven of seven Terminalia (excluding T1) individuals exhibiting consistently positive coefficients for this depth (Fig. 2a and b, Table C1). No tree yielded a consistent positive coefficient (i.e., a positive value in $>90 \%$ of the lasso runs) at any other depth, suggesting strong support for deep water as a driver of sap flow for both tree species in this system. Terminalia (but not Pterocarpus) trees consistently yielded negative coefficients for $\mathrm{VWC}_{10}$, which we interpret as reflecting a possible tradeoff between deep and shallow soil moisture availability. These results largely held when the weather station data were included in the regressions (Appendix D: Table D1), suggesting that soil moisture availability retains predictive power for explaining sap flow after accounting for variation in light availability and atmospheric conditions: 10 of 15 trees retained positive $\mathrm{VWC}_{40}$ coefficients, with two and one trees retaining positive coefficients for $\mathrm{VWC}_{20}$ and $\mathrm{VWC}_{10}$, respectively (Table D1). 
For the soil moisture only model, both $-T_{\mathrm{c}}$ and $-\Delta T$ yielded positive VWC coefficients at $5 \mathrm{~cm}$ and negative or zero (or negligible) coefficients at other depths in all four cases, suggesting that variation in grass canopy temperature is most closely associated with soil moisture availability in the uppermost layer of the soil (Fig. 2c and d, Table D1). These results were strengthened when the weather covariates were included (Table D1). Our regression also suggested a strong positive relationship between $T_{\mathrm{c}}$ (and $\Delta T$ ) and net radiation, consistent with other work on canopy temperature in $\mathrm{C}_{4}$ plants (Stefan et al. 2014). Overall, our regression models explained between $31 \%$ and $70 \%$ of the variance in sap flow or canopy temperature (excluding tree T1, Appendix E: Fig. E1). Our simulation study suggested that the lasso is able to reliably identify the true driving variable in a data set with the multicollinearity and signal-to-noise ratio typical of our data (Fig. E1). Although a nontrivial proportion of model runs incorrectly assigned positive coefficients to variables that should have had no effect on the simulated response, the actual coefficient values in these cases were substantially smaller than the values estimated for the true driving variable (Appendix F: Fig. F1).

\section{Discussion}

Our results supported our hypothesis, revealing treegrass differences in functional rooting depth at our site, and suggested that trees responded primarily to deep soil moisture availability while grasses responded to water in the uppermost soil layer. This is consistent with the notion of resource partitioning. Our results show that a significant amount of infiltration occurs beyond the shallowest soil layer at this site, particularly following extreme precipitation events (Fig. 1a), and that deep soil layers retain soil moisture for a significant proportion of the growing season. Previous work using tracers has revealed that trees and grasses differ (clearly but subtly) in terms of functional rooting depth in a similar site in nearby Kruger National Park (Kulmatiski et al. 2010, Kulmatiski and Beard 2013a). These authors also found that trees (but not grasses) appear to be highly plastic in their uptake patterns, using shallow soil moisture early in the season and shifting to sources below $30 \mathrm{~cm}$ depth later in the season (Kulmatiski and Beard 2013a). Our results bolster the case for rooting separation, but also suggest that water use differences between trees and grasses are detectable even when such plasticity is not accounted for, suggesting that the signal imposed by resource partitioning persists despite any seasonal shifts in tree-root reallocation.

A rigorous quantitative comparison of tree and grass transpiration data would be difficult with our current data set because we lack calibration data to relate $T_{\mathrm{c}}$ and $\Delta T$ to stomatal conductance. Even in the absence of such a calibration, however, we can show qualitatively that grass canopy temperature time series provide enough information to make inferences about likely sources of soil moisture for transpiration. Sap-flow techniques are well established in ecosystem science, but thermal analyses of canopy temperature data are not. Canopy temperature data and the associated CWSI are primarily used as tools for the detection of moisture stress in agricultural applications, and have repeatedly been shown to provide accurate quantitative indices of leaf pressure potential and stomatal conductance under field conditions (Jones 1999, Cohen et al. 2005, Ben-Gal et al. 2009). We believe that both sap flow and canopy temperature data can play important roles for resolving key questions in ecohydrology at the population and community level, and further our understanding of treegrass interactions at the scale of individual plants. In our particular case, an important next step will be the development of a more quantitative understanding of how uptake is partitioned across soil layers, something that will require the use of a mechanistic (as opposed to statistical) model of water uptake (e.g., Ogle et al. 2004).

Our soil moisture time series show that over the course of the growing season the vertical distribution of water availability is highly dynamic, exhibiting multiple inversions (the wettest layers switch from shallow to deep and back again) and shifts from being distributed homogeneously to heterogeneously. The occurrence and persistence of these inversions and vertical heterogeneity are primarily a function of the key driver in the system, precipitation, and the role that the soil substrate plays on infiltration rates (soils with high clay fractions, such as the Serengeti Acacia savannas, may provide fewer opportunities for resource partitioning). We suggest that modifications in precipitation regimes may exert complex, nonlinear effects on soil moisture distribution, and that ultimately an understanding of plant water use and biomass dynamics in these systems requires a melding of soil moisture dynamics models, detailed information on plant rooting profiles, and aboveground plant physiological responses.

A future goal for these systems should be the development of quantitative models that can project plant growth and the strength of competitive interactions between trees and grasses as a function of precipitation. Our results, and those of prior researchers (Kambatuku et al. 2013, Kulmatiski and Beard 2013a, b) suggest that depth-resolved tree-grass rooting differences should be taken into account as part of this process. For example, a recent experiment conducted in Kruger National Park found that infrequent but large precipitation events tend to favor trees at the expense of grasses, while frequent, small events favor grasses (Kulmatiski and Beard 2013b), and the difference was attributable to the deeper infiltration (reaching deeper roots) that occurs in the former scenario. We note that not all work in this system supports the notion of niche partitioning (e.g., Verweij et al. 2011, February et al. 2013), suggesting that the conditions under which it occurs may well vary, and the causes of this variation require further investigation. We propose that a next

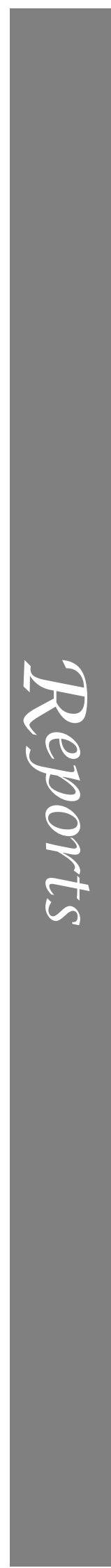


step for moving the field forward should be the estimation (rather than detection) of niche-partitioning and tree-grass competition coefficients across key environmental gradients (e.g., rainfall).

\section{ACKNOWLEDGMENTS}

Wayne Twine and Wits University provided access to the field site at Wits Rural Facility. We thank Sally Archibald for guidance on the use of IRTs. This research was funded in part by a grant from the Andrew W. Mellon Foundation and by the University of Missouri. We thank two anonymous reviewers for helpful comments on a previous version of the manuscript.

\section{Literature Cited}

Ben-Gal, A., N. Agam, V. Alchanatis, Y. Cohen, U. Yermiyahu, I. Zipori, E. Presnov, M. Sprintsin, and A. Dag. 2009. Evaluating water stress in irrigated olives: correlation of soil water status, tree water status, and thermal imagery. Irrigation Science 27:367-376.

Cohen, Y., V. Alchanatis, M. Meron, Y. Saranga, and J. Tsipris. 2005. Estimation of leaf water potential by thermal imagery and spatial analysis. Journal of Experimental Botany 56:1843-1852.

Corbin, J., M. Thomsen, T. Dawson, and C. D'Antonio. 2005. Summer water use by California coastal prairie grasses: fog, drought, and community composition. Oecologia 145:511521.

February, E. C., S. I. Higgins, W. J. Bond, and L. Swemmer. 2013. Influence of competition and rainfall manipulation on the growth responses of savanna trees and grasses. Ecology 94:1155-1164.

Friedman, J., T. Hastie, and R. Tibshirani. 2010. Regularization paths for generalized linear models via coordinate descent. Journal of Statistical Software 33:1-22.

Granier, A. 1985. Une nouvelle methode pour la mesure du flux de seve brute dans le tronc des arbres. Annales des Sciences Forestieres 42:193-200.

Holdo, R. M. 2013. Revisiting the two-layer hypothesis: coexistence of alternative functional rooting strategies in savannas. PLoS ONE 8:e69625.

Jones, H. G. 1999. Use of thermography for quantitative studies of spatial and temporal variation of stomatal conductance over leaf surfaces. Plant, Cell \& Environment 22:1043-1055.

Kambatuku, J. R., M. D. Cramer, and D. Ward. 2013. Overlap in soil water sources of savanna woody seedlings and grasses. Ecohydrology 6:464-473.

Knoop, W. T., and B. H. Walker. 1985. Interactions of woody and herbaceous vegetation in a southern African savanna. Journal of Ecology 73:235-253.

Kulmatiski, A., and K. Beard. 2013a. Root niche partitioning among grasses, saplings, and trees measured using a tracer technique. Oecologia 171:25-37.

Kulmatiski, A., and K. H. Beard. 2013b. Woody plant encroachment facilitated by increased precipitation intensity. Nature Climate Change 3:833-837.

Kulmatiski, A., K. H. Beard, R. J. T. Verweij, and E. C. February. 2010. A depth-controlled tracer technique measures vertical, horizontal and temporal patterns of water use by trees and grasses in a subtropical savanna. New Phytologist 188:199-209.

Lazaridis, D. C., J. Verbesselt, and A. P. Robinson. 2010. Penalized regression techniques for prediction: a case study for predicting tree mortality using remotely sensed vegetation indices. Canadian Journal of Forest Research 41:24-34.

Möller, M., V. Alchanatis, Y. Cohen, M. Meron, J. Tsipris, A. Naor, V. Ostrovsky, M. Sprintsin, and S. Cohen. 2007. Use of thermal and visible imagery for estimating crop water status of irrigated grapevine. Journal of Experimental Botany 58:827-838.

Mordelet, P., J.-C. Menaut, and A. Mariotti. 1997. Tree and grass rooting patterns in an African humid savanna. Journal of Vegetation Science 8:65-70.

Nippert, J., and A. K. Knapp. 2007. Linking water uptake with rooting patterns in grassland species. Oecologia 153:261-272.

Ogle, K., R. L. Wolpert, and J. F. Reynolds. 2004. Reconstructing plant root area and water uptake profiles. Ecology 85:1967-1978.

Paço, T. A., T. S. David, M. O. Henriques, J. S. Pereira, F. Valente, J. Banza, F. L. Pereira, C. Pinto, and J. S. David. 2009. Evapotranspiration from a Mediterranean evergreen oak savannah: the role of trees and pasture. Journal of Hydrology 369:98-106.

Riginos, C. 2009. Grass competition suppresses savanna tree growth across multiple demographic stages. Ecology 90:335340 .

Rodríguez-Iturbe, I., P. D'Odorico, A. Porporato, and L. Ridolfi. 1999. Tree-grass coexistence in savannas: the role of spatial dynamics and climate fluctuations. Geophysical Research Letters 26:247-250.

Roux, X. L., T. Bariac, and A. Mariotti. 1995. Spatial partitioning of the soil water resource between grass and shrub components in a West African humid savanna. Oecologia 104:147-155.

Sala, O. E., R. A. Golluscio, W. K. Lauenroth, and A. Soriano. 1989. Resource partitioning between shrubs and grasses in the Patagonian steppe. Oecologia 81:501-505.

Stefan, S., E. Frank, R. Ehsan Eyshi, K. Henning, and G. Rikard. 2014. Impact of heat stress on crop yield - on the importance of considering canopy temperature. Environmental Research Letters 9:044012.

Tibshirani, R. 1996. Regression shrinkage and selection via the lasso. Journal of the Royal Statistical Society B (Methodological) 58:267-288.

Verweij, R. J. T., S. I. Higgins, W. J. Bond, and E. C. February. 2011. Water sourcing by trees in a mesic savanna: responses to severing deep and shallow roots. Environmental and Experimental Botany 74:229-236.

Ward, D., K. Wiegand, and S. Getzin. 2013. Walter's two-layer hypothesis revisited: back to the roots! Oecologia 172:616630.

Weltzin, J. F., and G. R. McPherson. 1997. Spatial and temporal soil moisture resource partitioning by trees and grasses in a temperate savanna, Arizona, USA. Oecologia 112:156-164.

West, A. G., E. C. February, and G. J. Bowen. 2014. Spatial analysis of hydrogen and oxygen stable isotopes ("isoscapes") in ground water and tap water across South Africa. Journal of Geochemical Exploration 145:213-222.

\section{Supplemental Material}

\section{Ecological Archives}

Appendices A-F are available online: http://dx.doi.org/10.1890/14-1986.1.sm 